\title{
Drug delivery through soft contact lenses
}

\author{
M R JAIN
}

From the Department of Ophthalmology, New Teaching Medical College Hospital, Jodhpur, India

SUMmARY Clinical studies were conducted on 466 patients waiting for senile cataract surgery and receiving chloromycetin, gentamicin, or carbenicillin subconjunctivally and through New Sauflon 70 and New Sauflon 85 lenses. The aqueous drug levels were biologically estimated at various time intervals. Soft contact lenses provided significantly higher drug penetration than subconjunctival therapy. Both modes of treatment provided therapeutically effective levels against most of the common ocular pathogens for varying intervals of 2 to 12 hours.

Soft contact lenses were initially used for drug delivery by Sedlavek in Czechoslovakia in 1965,' and since then many workers have advocated their use with various drugs. The hydrogel lenses, by virtue of their high water content and large intermolecular pore size, absorb water soluble drugs with some correlation with molecular weight, releasing them initially in a high pulse and then gradually, thereby complying with first order kinetics. However, the first order kinetics can be advantageously turned into practically zero order kinetics where sustained high concentration of the drug is obtained by superinstillation of drops at two- to four-hour intervals or reapplication of a soaked lens, depending on the need and severity of the condition. ${ }^{2}$

Anterior segment inflammations, whether infective or allergic, and angle closure glaucoma are a few of the important clinical conditions requiring a high intraocular concentration of drugs. The drugs which can be conveniently delivered are the water soluble antibiotics, steroids (betamethasone, dexamethasone, and prednisolone), pilocarpine, atropine, and homatropine.

The author has conducted various sets of clinical studies with the following aims: (1) to estimate and compare the penetration of various antibiotics into the aqueous after subconjunctival injection and soft contact lens delivery in relation to dosage and time; (2) to compare the drug penetration with hydrogel lenses of different water content.

\section{Material and methods}

The studies were conducted on 466 patients awaiting

Correspondence to Professor M R Jain, Department of Ophthalmology, New Teaching Hospital and Dr SN Medical College, Jodhpur, India. surgery for senile cataract. Eyes suffering from any kind of disease were not included in this study. The time of cataract incision was so planned as to provide a predetermined dose-to-sample time interval.

In the subconjunctival group of cases the specified dose of antibiotic dissolved in $0.5 \mathrm{ml}$ of distilled water was injected subconjunctivally, and the cases were divided into various subgroups depending on the dose-to-sample interval which varied over $1 / 4,1 / 2,1$, $2,4,8$, and 12 hours.

In the other group of cases soft contact lenses were used to deliver the drugs. The lenses employed were of two different water contents, namely, New Sauflon 70 and New Sauflon 85 (supplied by CLM, London). These lenses were afocal, of uniform thickness $(0 \cdot 2$ $\mathrm{mm})$, and of uniform diameter $(14.0 \mathrm{~mm})$; they had varying base curves of 8.0 to $9.0 \mathrm{~mm}$. Each lens was soaked for half an hour in freshly prepared $0.5 \mathrm{ml}$ solution containing the specified dose of antibiotic. Thereafter the lens was taken out, placed on a sterile filter paper for 5 seconds, applied to the anaesthetised cornea for half an hour, and then removed. Aqueous samples were collected at the time of operation and at various time intervals, namely, $1 / 4$, $1 / 2,1,2,4$, and 6 hours in different groups of patients.

Subconjunctival group (224 eyes). Drug doses and number of eyes studied: $(a)$ chloromycetin sodium succinate $50 \mathrm{mg}$ ( 65 eyes); (b) carbenicillin $50 \mathrm{mg}$ (69 eyes); (c) gentamicin sulphate $20 \mathrm{mg}$ (90 eyes).

Soft contact lenses group (242 eyes). Drug doses and number of eyes studied: (1) New Sauflon 70 lenses-(a) chloromycetin sodium succinate $50 \mathrm{mg}$ (55 eyes), (b) carbenicillin $50 \mathrm{mg}$ (35 eyes); (2) New Sauflon 85 lenses- (a) carbenicillin $50 \mathrm{mg}$ (42 eyes), (b) gentamicin sulphate $20 \mathrm{mg}$ (60 eyes), (c) chloromycetin sodium succinate $50 \mathrm{mg}$ (50 eyes).

After aspiration of aqueous samples, the bio- 
Table 1 Mean aqueous concentration of various antibiotics at various time intervals after subconjunctival injections and the use of soft lenses (Sauflon 70 and 85 ) in 466 eyes

\begin{tabular}{|c|c|c|c|c|c|c|c|c|}
\hline \multirow{3}{*}{$\begin{array}{l}\text { Time interval } \\
\text { in hours after } \\
\text { removal of } \\
\text { lens and after } \\
\text { subconjunctival } \\
\text { injection }\end{array}$} & \multicolumn{8}{|c|}{ Antibiotic penetration $(\mu \mathrm{g} / \mathrm{ml}$ with $S D)$} \\
\hline & \multicolumn{3}{|c|}{ Chloromycetin $50 \mathrm{mg}$} & \multicolumn{3}{|c|}{ Carbenicillin $50 \mathrm{mg}$} & \multicolumn{2}{|c|}{ Gentamicin $20 \mathrm{mg}$} \\
\hline & $\begin{array}{l}\text { Subconj. } \\
\text { inj. }\end{array}$ & $\begin{array}{l}\text { Sauflon } \\
70\end{array}$ & $\begin{array}{l}\text { Sauflon } \\
85\end{array}$ & $\begin{array}{l}\text { Subconj. } \\
\text { inj. }\end{array}$ & $\begin{array}{l}\text { Sauflon } \\
70\end{array}$ & $\begin{array}{l}\text { Sauflon } \\
85\end{array}$ & $\begin{array}{l}\text { Subconj. } \\
\text { inj. }\end{array}$ & $\begin{array}{l}\text { Sauflon } \\
85\end{array}$ \\
\hline $1 / 4$ & $4 \cdot 35 \pm 2 \cdot 21$ & $11 \cdot 25 \pm 1 \cdot 13$ & $24 \cdot 14 \pm 2 \cdot 24$ & $38.8 \pm 6.69$ & $81 \cdot 9 \pm 17 \cdot 92$ & $148 \cdot 60 \pm 26 \cdot 64$ & $3 \cdot 53 \pm 1 \cdot 78$ & $10 \cdot 79 \pm 0 \cdot 601$ \\
\hline $1 / 2$ & $13 \cdot 275 \pm 4.93$ & $19 \cdot 35 \pm 4 \cdot 13$ & $29 \cdot 75 \pm 0 \cdot 74$ & $80 \cdot 5 \pm 10.90$ & $70 \cdot 1 \pm 21 \cdot 13$ & $136 \cdot 40 \pm 12 \cdot 62$ & $5 \cdot 14 \pm 2 \cdot 10$ & $35 \cdot 25 \pm 6 \cdot 750$ \\
\hline 1 & $16 \cdot 24 \pm 1 \cdot 92$ & $13 \cdot 20 \pm 2 \cdot 57$ & $22 \cdot 10 \pm 3 \cdot 70$ & $69.5 \pm 7 \cdot 36$ & $31 \cdot 3 \pm 6 \cdot 25$ & $64 \cdot 20 \pm 14 \cdot 37$ & $14 \cdot 62 \pm 1 \cdot 92$ & $21 \cdot 38 \pm 2 \cdot 242$ \\
\hline 2 & $12 \cdot 275 \pm 1 \cdot 90$ & $9 \cdot 75 \pm 2 \cdot 32$ & $6 \cdot 75 \pm 1 \cdot 88$ & $32 \cdot 0 \pm 6.99$ & $6.8 \pm 1.89$ & $28.0 \pm 9.41$ & $12 \cdot 42 \pm 2 \cdot 84$ & $12 \cdot 50 \pm 2 \cdot 953$ \\
\hline 4 & $10 \cdot 215 \pm 1 \cdot 05$ & Nil & $4 \cdot 66 \pm 1 \cdot 29$ & $12 \cdot 9 \pm 4 \cdot 10$ & Nil & Nil & $10 \cdot 21 \pm 4 \cdot 68$ & $6 \cdot 13 \pm 0 \cdot 840$ \\
\hline 6 & ND & - & Nil & ND & - & - & ND & $1 \cdot 75 \pm 1 \cdot 00$ \\
\hline 8 & $4 \cdot 325 \pm 0 \cdot 68$ & - & - & Nil & - & - & $8 \cdot 10 \pm 3 \cdot 12$ & ND \\
\hline 12 & Nil & - & - & Nil & - & - & $6 \cdot 64 \pm 1 \cdot 28$ & - \\
\hline 18 & - & - & - & - & - & - & $\mathrm{Nil}$ & - \\
\hline 24 & - & - & - & - & - & - & Nil & - \\
\hline No. of eyes & 65 & 55 & 50 & 69 & 35 & 42 & 90 & 60 \\
\hline
\end{tabular}

$\mathrm{ND}=$ Not done.

estimation was done by a modified disc diffusion method using Bacillus subtilis NCIM 2062 as the assay organism.

\section{Results}

Table 1 shows the mean values of antibiotics with standard deviation in the aqueous at various time intervals after subconjunctival injection and the use of Sauflon 70 and Sauflon 85 lenses (466 eyes).

It is notable that, after subconjunctival injections, the antibiotics penetrated within 15 minutes, attained their maximum concentration within 30 to 60 minutes, and thereafter declined, but maintained quite a high concentration up to four hours. They were not traceable in samples collected at 8 to 18 hours. It is also evident from Table 1 that soft contact lenses provided very high penetration into the aqueous within 15 minutes; the drugs attained their peak level within 30 minutes and thereafter rapidly fell. Within four to six hours the samples were almost free of antibiotics.

Figs. 1, 2, and 3 show comparative concentrations of different antibiotics when given subconjunctivally and through soft contact lenses. It is notable that with soft contact lenses the peak concentration of antibiotics in aqueous occurred quickly, but it showed a rapid decline as compared with the subconjunctival group. Sauflon 85 provided almost double the drug penetration in the first three samples collected up to one hour as compared with Sauflon 70. After one hour the deline in the Sauflon 85 group was too rapid, and there was hardly any difference in the duration of penetration in soft lenses of different water content.

\section{Discussion}

Because of tear flow, topically instilled drugs have a limited life span in the conjunctival sac, and only a fraction of their mass penetrates the eyeball across the epithelial barrier of the cornea. The resistance of corneal epithelium to ions is about 2000 times that of the total stroma. The relative thickness of epithelium, stroma, and endothelium is $0 \cdot 1: 10: 0 \cdot 01$, and the relative resistance to diffusion of electrolytes by these structures is $2000: 1 \cdot 0: 10 \cdot 0$. This results in drug penetration in many cases in quantities which is below the optimum required for treatment. ${ }^{34}$ Drug penetration may be marginally improved by retention of the instilled drug for slightly longer in the conjunctival sac, by frequent instillation, by increasing the viscosity of the drug with methylcellulose or polyvinyl alcohol as a vehicle, by using the drug in ointment or suspension form, or by making the drug more alkaline. ${ }^{5}$

However, much better penetration can be achieved by prolonging the contact time of the drug in the eye. Hydrophilic contact lenses as an adjuvant to drug delivery have given results. ${ }^{-a-4}$ Drugs penetrate hydrophilic contact lenses at a rate which depends on the pore size between the cross linkages of the threedimensional lattice structure of the lens, on the concentration of the drug in the solution, and on the molecular size of the drug. "Waltman and Kaufman" used fluorescein as a model drug with bionite (Griffin) and Soflens (Bausch and Lomb) lenses in rabbit eyes and observed that the amount of drug taken up by a lens varied with the material of the lens, primarily depending on its water content. 


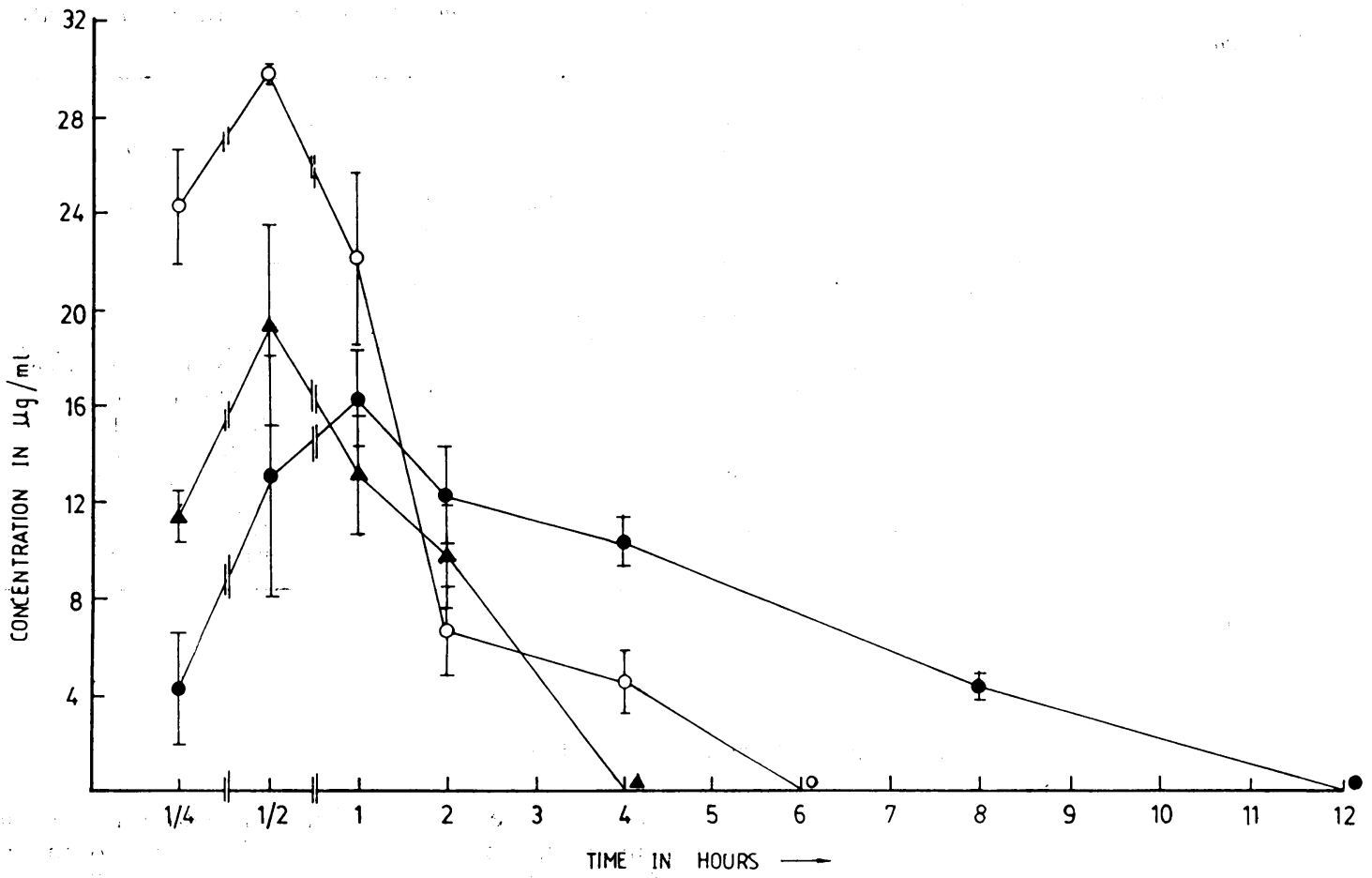

Fig. 1 Comparative levels of chloramphenicol in 170 eyes. $\mathbf{O}=$ Subconjunctival injection. $\mathbf{\Delta}=$ Sauflon $70 . \bigcirc=$ Sauflon 85 .

Most of the studies of soaking time have been confined to pilocarpine solution only. Podos et al. ${ }^{12}$ observed that with a $0 \cdot 5 \%$ solution of pilocarpine the drug uptake appears to increase with the time of immersion, approaching a maximum after soaking the lens for 30 to 60 minutes. Preliminary biochemical studies conducted by Hillman "s showed that approximately 24 hóurs' soaking is necessary to saturate a
Sauflon lens, which then holds 400 to $500 \mu \mathrm{g}$ of pilocarpine.

The release rate of pilocarpine from the soft lens in vivo and in vitro has an approximate half life of 30 minutes, and almost all the pilocarpine is leached out after four hours of lens wear. ${ }^{11}$ In contrast to a 2minute soak advocated by Podos et al. ${ }^{12}$ a 30-minute soak was used in the present study, because Hillman ${ }^{10}$
Fig. 2 Comparative levels of carbennicillin in 146 eyes. Symbols as in Fig. 1.

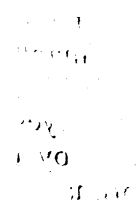






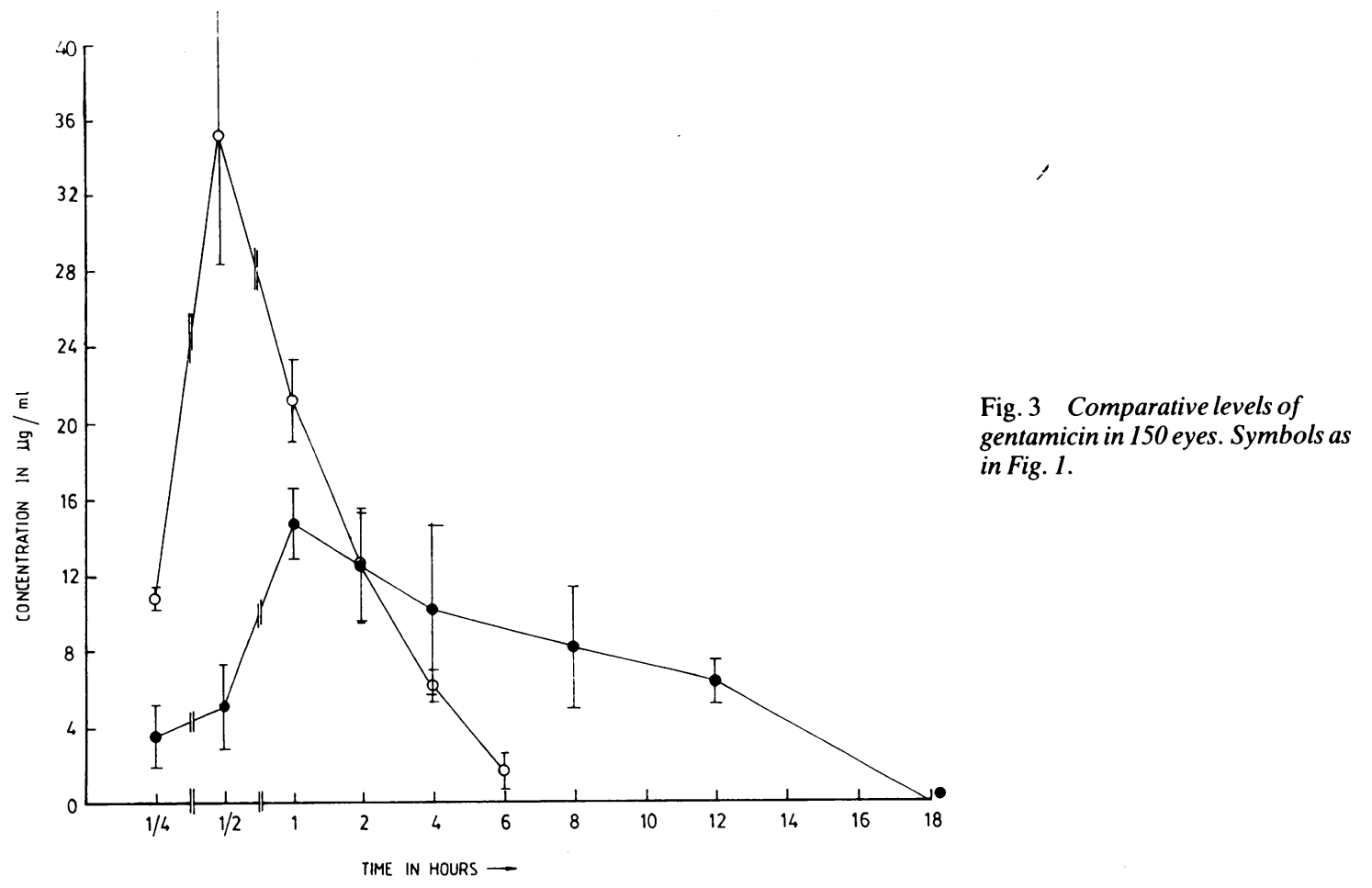

observed that a 30-minute soak allows equilibration throughout the lens, so that when the drug diffuses out from the surface layers it is replenished from the deep part of the lens, which acts as a reservoir producing a more sustained high yield. Hillman ${ }^{10}$ further observed that a prolonged soak to a state of equilibrium produced a more standardised form of presoaked lens. Half an hour's wear was practised in the present study, since Podos et al. ${ }^{12}$ concluded that this period is the shortest that will provide maximum concentration of the drug to ocular tissues.

Subconjunctival therapy is the most widely practised, for it provides quick and prolonged penetration of water soluble drugs into the aqueous. The advantage of subconjunctival injection is that it shortcircuits the essential barrier set up by the epithelium of the cornea and conjunctiva to the entrance of substances into the eye. The permeability of the sclera corresponds to and is even greater than that of the corneal stroma. ${ }^{13-15}$ The corneal stroma allows diffusion of most solutes under a certain molecular weight with a cut-off point of $50000 .^{4}$

Absorption into the interior of the eye is essentially a process of diffusion through the tissues, not, as is sometimes said, through the circulation. This fact has been proved by an observation where better intraocular concentration was noted in a freshly killed animal than in a living animal and by the fact that the addition of a vasoconstrictor drug increases the penetration. ${ }^{13}$ Corneal stroma also permits easy diffusion of subconjunctivally injected fluid, as it bypasses the barrier of corneal epithelium. ${ }^{16}$ The observed aqueous humour concentration of the subconjunctivally injected drugs (Table 1) is almost double the reported minimum inhibitory concentration (Table 2) ${ }^{17}$ against most of the common ocular pathogens. In such concentrations some antibiotics

Table 2 Minimum inhibitory concentration of gentamicin, carbenicillin, and chloramphenicol required for common ocular pathogens ${ }^{17}$

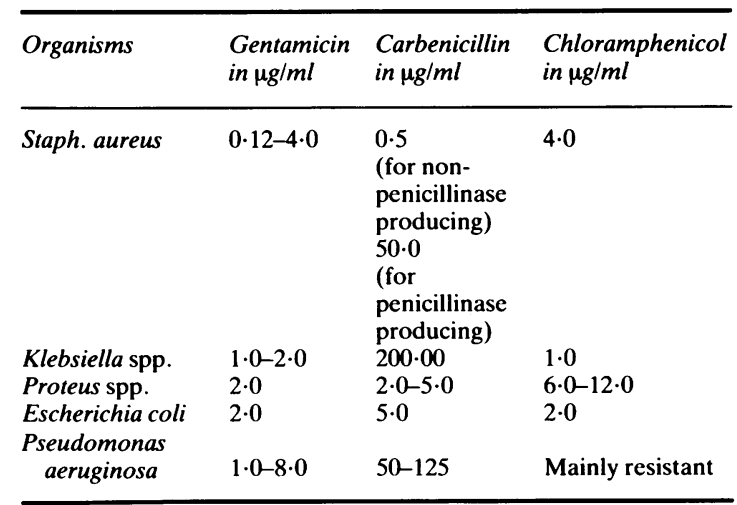


such as chloramphenicol, which is essentially bacteriostatic, may act as a bactericidal drug for varying intervals of time. ${ }^{18}$ However, the therapeutic level lasts for only six to eight hours, and hence in severe infections the subconjunctival therapy may have to be repeated twice or thrice to provide consistently high drug concentrations.

\section{MERITS OF SOFT LENS DELIVERY SYSTEM}

A distinct merit of the soft lens delivery system is the higher drug penetration than by subconjunctival therapy. In agreement with Waltmann and Kaufman ${ }^{11}$ we noted that the drug penetration was significantly greater when lenses of higher water content were used. These observations may favour the use of this mode of treatment when high intraocular penetration of drug is needed. Another notable merit of the hydrogel delivery system may be the need for much smaller amounts of drugs to produce the desired therapeutic levels. ${ }^{919}$ Since less drug is delivered to the eye per unit of time, fewer side effects may be expected. Thus drugs that previously could not be used because of adverse side effects or excessive toxicity might be considered for therapeutic use at lower concentration. ${ }^{19} \mathrm{~A}$ more obvious advantage is to those patients who are apprehensive about a prick in the eye, which can cause some ocular discomfort or pain or chemosis or even subconjunctival haemorrhage, especially when repeated injections are needed.

\section{DISADVANTAGES OF SOFT LENS DELIVERY SYSTEM}

Drug release from a hydrogel contact lens is pulselike, with an initial peak followed by a gradual decline (first order kinetics). This may necessitate repeated application of drug soaked lenses in cases which require consistently high drug penetration. In addition a proper fitting of a hydrogel contact lens is in itself a procedure not entirely devoid of complications and added expense. Moreover, prolonged wear of a contact lens may lead to intolerance, corneal vascularisation, lens deposits and spoilage, giant papillary conjunctivitis, lens loss, and corneal ulceration.

To conclude, it may be stated that the hydrogel contact lens delivery system may be an effective method of treating some of the infective conditions of anterior segments of the eye in patients who are not suitable for subconjunctival therapy or in whom there is a reason to use a minimum quantity of drug.

\section{References}

1 Sedlavek J. Possibilities of application of ophthalmic drugs with the aid of gel contact lens. Cesk Oftalmol 1965; 21: 509-14.

2 Jain MR, Batra V. Steroid penetration in human aqueous with Sauflon 70 lenses. Indian J Ophthalmol 1970; 11: 26-31.

3 Maurice DM. The permeability to sodium ions of the living rabbit cornea. J Physiol (Lond) 1951; 112: 367-71.

4 Maurice DM. Structures and fluids involved in the penetration of topically applied drugs. International ophthalmic clinics. Boston: Little, Brown, 1960: 20: 7-20.

5 Maurice DM. Factors influencing the penetration of topically applied drugs. International ophthalmic clinics. Boston: Little, Brown, 1980: 20: 21-32.

6 Asseff CF, Weisman RL, Podos SM, Becker B. Ocular penetration of pilocarpine in primates. Am J Ophthalmol 1973; 75: 212-5.

7 Hull DS, Edelhauser HF, Hyndiuk RA. Ocular penetration of prednisolone and hydrophilic contact lens. Arch Ophthalmol 1974; 92: 413-6.

8 Kaufman HE, Uotila MH, Gasset AR, et al. The medical uses of soft contact lenses. Ophthalmology 1971; 75: 361-73.

9 Marmion VJ, Jain MR. Role of soft contact lenses and delivery of drugs. Trans Ophthalmol Soc UK 1976; 96: 319-21.

10 Hillman JS. Management of acute glaucoma with pilocarpine soaked hydrophilic lens. Br J Ophthalmol 1974; 58: 674-9.

11 Waltman SR, Kaufman HE. Use of hydrophilic contact lenses to increase ocular penetration of topical drugs. Invest Ophthalmol Vis Sci 1970; 9: 250-5.

12 Podos SM, Becker B, Asseff CF, Harstein J. Pilocarpine therapy with soft contact lenses. Am J Ophthalmol 1972; 73: 336-41.

13 Duke-Elder S. System of ophthalmology. London: Kimpton, 1962: 8: 514-6.

14 Jain MR, Srivastava S. Ocular penetration of hydrocortisone and dexamethasone into the aqueous humour after subconjunctival injection. Trans Ophthalmol Soc UK 1978; 98: 63-5.

15 Wine NA, Gornall AC, Basu PK. Ocular uptake of subconjunctivally injected C-14 hydrocortisone. Am J Ophthalmol 1964; 58: 362-5.

16 Friend J. Biochemistry of ocular surface epithelium. International ophthalmology clinics. Boston: Little, Brown, 1979: 19: 73-91.

17 Briant MC. Antibiotics and their laboratory control. London: Butterworths, 1972: 10-14.

18 Smolin G, Thoft RA. The cornea: antibiotic mechanisms. Boston: Little, Brown, 1983: 134-43.

19 Lerman S, Reininger B. Simulated sustained release pilocarpine therapy and aqeous humour dynamics. Can J Ophthalmol 1971: 6: $14-23$.

Accepted for publication 15 December 1986. 